\title{
MULTIMODAL EVOKED POTENTIALS AND THE OVARIAN CYCLE IN YOUNG OVULATING WOMEN
}

\author{
LUIZ ANTONIO DE LIMA RESENDE*, MARIA DORVALINA SILVA**, \\ FABIOLLA IMPEMBA**, NÍDIA BORGES ACHÔA**, ARTHUR OSCAR SCHELP*.
}

\begin{abstract}
There is controversy over how hormonal conditions influence cerebral physiology. We studied pattern-shift visual evoked potentials (PS-VEP), brain stem auditory evoked potentials (BAEP) and short-latency somatosensory evoked potentials (SSEV) in 20 female volunteers at different phases of the menstrual cycle (estrogen phase, ovulatory day and progesterone phase). Statistical analysis showed decreased latencies for $\mathrm{P}_{100}$ (PS-VEP), $\mathrm{N}_{19}$ and $\mathrm{P}_{22}$ (SSEV) waves in the progesterone phase compared with the estrogen phase. There was no significant difference between the estrogen and the ovulation day values. Comparing the three above stages, there were no significant differences in the brainstem auditory evoked potentials. The reduction of the latencies of the potentials generated in multisynaptic circuits provides the first consistent neurophysiological basis for a tentative comprehension of human pre-menstrual syndrome.
\end{abstract}

KEY WORDS: evoked potentials, multimodal, ovarian cycle.

\section{Potenciais evocados nas diferentes fases do ciclo menstrual da mulher}

RESUMO - Há controvérsias sobre como variações hormonais do ciclo menstrual da mulher influenciam a neurofisiologia cerebral. Estudamos potenciais evocados de curta latência, visuais, auditivos e sômato-sensoriais, em 20 mulheres voluntárias normais, nas diferentes fases do ciclo menstrual (fase estrogênica, fase ovulatória, fase progestacional). Comparação entre fase estrogênica e ovulatória mostrou resultados similares. Ondas I, III, $\mathrm{V}$ dos potenciais evocados auditivos não apresentaram diferenças estatisticamente significativas entre as três fases do ciclo. Análise estatística dos resultados mostrou diminuição significativa das latências das ondas P100, N19 e P22 obtidas na fase progestacional, comparadas com aquelas obtidas na fase estrogênica. Como estas ondas são geradas em circuitos multissinápticos, tal redução de latências, na fase progestacional, fornece a primeira base neurofisiológica consistente para tentativa de compreensão da síndrome pré-menstrual da mulher.

PALAVRAS-CHAVE: potenciais evocados, multimodais, ciclo menstrual.

The menstrual cycle influences different clinical conditions such as atopic dermatitis ${ }^{1}$, diabetes, asthma, rheumatoid arthritis ${ }^{2}$, pulmonary edema, cardiac arrithmias and gastrointestinal dysfunctions ${ }^{3}$. Catamenial hemoptisis, catamenial hemothorax and catamenial hemopneumothorax are all well documented clinical conditions ${ }^{4}$. In neurology, illnesses such as myastenia gravis, multiple sclerosis, arteriovenous aneurysms, meningioma, epilepsy, and migraine may be worse during the catamenial or pre-menstrual phases ${ }^{3,5-7}$. EEG also varies during different phases of the menstrual cycle ${ }^{8}$.

There is controversy over how hormonal conditions influence cerebral physiology. Some authors ${ }^{9}$, analyzing brainstem auditory evoked potentials (BAEP), found a significant increase in wave III and V latencies, as well as the I-V intervals, associated with elevated levels of estrogen in the luteal phase. No significant differences in latencies were found in ovulatory cycles comparing

Department of Neurology and Psychiatry, Faculty of Medicine of Botucatu of the State University of São Paulo (UNESP): *Assistent-Professor; ** Medical Resident. Aceite: 9-março-2000.

Dr. Luiz A. L. Resende - Department of Neurology and Psychiatry, Faculty of Medicine of Botucatu - UNESP - 18618-000 Botucatu SP - Brasil. Fax 148215965. 
groups using and not using oral contraceptives. Other authors, however, comparing patients with or without pre-menstrual syndrome (late luteal phase dysphoric disorder) did not find variations in latencies of BAEP related to any phase of the menstrual cycle ${ }^{10}$. Differences were also observed in the latencies of pattern-shift visual evoked potentials (PS-VEP), with increased latencies in pregnant compared to non-pregnant women ${ }^{11}$. There is disagreement in medical literature about how hormonal variations from different phases of the menstrual cycle influence evoked potentials in women.

This study analyzes the PS-VEP, BAEP, and SSEP in a group of young ovulating women during three different hormonal stages of the menstrual cycle.

\section{METHOD}

Twenty young, normal white female medical volunteers (ages 23 to 26) participated in this study. They were made fully aware of the nature of the procedures and gave their formal consent. Only women with a clear knowledge of their ovulation were included. Patients not aware of their ovulation time (indicated by changes in vaginal secretion, cramps, and mood changes) and those using hormonal contraceptives or experiencing irregular cycles were excluded. In 5 volunteers the exact moment of ovulation was in the late evening or overnight, and the evoked potentials could not be obtained.

PS-VEP, BAEP and SSEP measurements were taken from the $2^{\text {nd }}$ to the $7^{\text {th }}$ day of the cycle (estrogenic phase - EP), on the day of ovulation (ovulatory phase - OP), and from the $6^{\text {th }}$ to the $1^{\text {st }}$ pre-menstrual day of the cycle (progesterone phase - PP).

Multimodal measurements were taken at random by the same examiner using a 2-channel Nihon-Kohden Neuropack II apparatus.

PS-VEP were generated with a 1 grade contrast -reversed pattern at $2 \mathrm{~Hz}$ stimulus. Analysis time was $300 \mathrm{~ms}$, band-pass filter 5 to $20 \mathrm{~Hz}$ and sensitivity $5 \mu \mathrm{V} / \mathrm{cm}$. A minimum of 2 series of 100 stimuli were averaged for each individual test. The records were analyzed for the left and right peak latencies of $\mathrm{P}_{100}$.

BAEPs were obtained in response to $15 \mathrm{~Hz}$ rarefaction clicks of $85 \mathrm{~dB}$ lasting $0.2 \mathrm{~ms}$. Analysis time was $10 \mathrm{~ms}$, band-pass filter 200 to $3,000 \mathrm{~Hz}$ and sensitivity $0,31 \mu \mathrm{V} / \mathrm{cm}$. A minimum of 2 series of 1000 stimuli were averaged for each individual test. The records were analyzed for the left latencies of waves I, III and V.

SSEPs were obtained in response to a $5 \mathrm{~Hz}$ square wave pulse of continuous electrical stimulus lasting $0,2 \mathrm{~ms}$ applied by $7 \mathrm{~mm}$ surface disc electrodes, $2 \mathrm{~cm}$ apart, on the right median nerve at the wrist. In each case the stimulus intensity was just above that necessary for minimal thumb movements. The analysis time was $50 \mathrm{~ms}$, band-pass filter 20 to $3,000 \mathrm{~Hz}$ and sensitivity $1.25 \mu \mathrm{V} / \mathrm{cm}$. A minimum of 2 series of 500 stimuli were averaged for each individual test.

Electrode positioning, nomenclature of the waves, and methodology was according to Chiappa ${ }^{12}$.

Statistical analysis was performed using the paired t-test.

\section{RESULTS}

Statistical analysis showed a decrease of latencies recorded for the $\mathrm{P}_{100}$ (PS-VEP), and $\mathrm{N}_{19}$ and $\mathrm{P}_{22}$ (SSEP) when the progesterone phase was compared with the estrogen phase. There was no significant difference between the estrogen and ovulatory phase SSEP when comparing the progesterone phase to the estrogen phase (Table 1).

No differences were recorded for BAEP when the three above refered phases of the menstrual cycle were compared (Table 1).

Examples of slight decreases in $\mathrm{P}_{100}$ latencies obtained in the progesterone phase in relation to the estrogen phase are shown in Figure 1.

Examples of slight decreases in $\mathrm{N}_{19}$ and $\mathrm{P}_{22}$ latencies obtained in progesteronic phase in relation to the estrogen phase are shown in Figure 2.

One patient became pregnant after her study cycle. One year later, during the last three months of the pregnancy, the potentials obtained were similar to the progesterone phase prior to the pregnancy (Figure 3). 


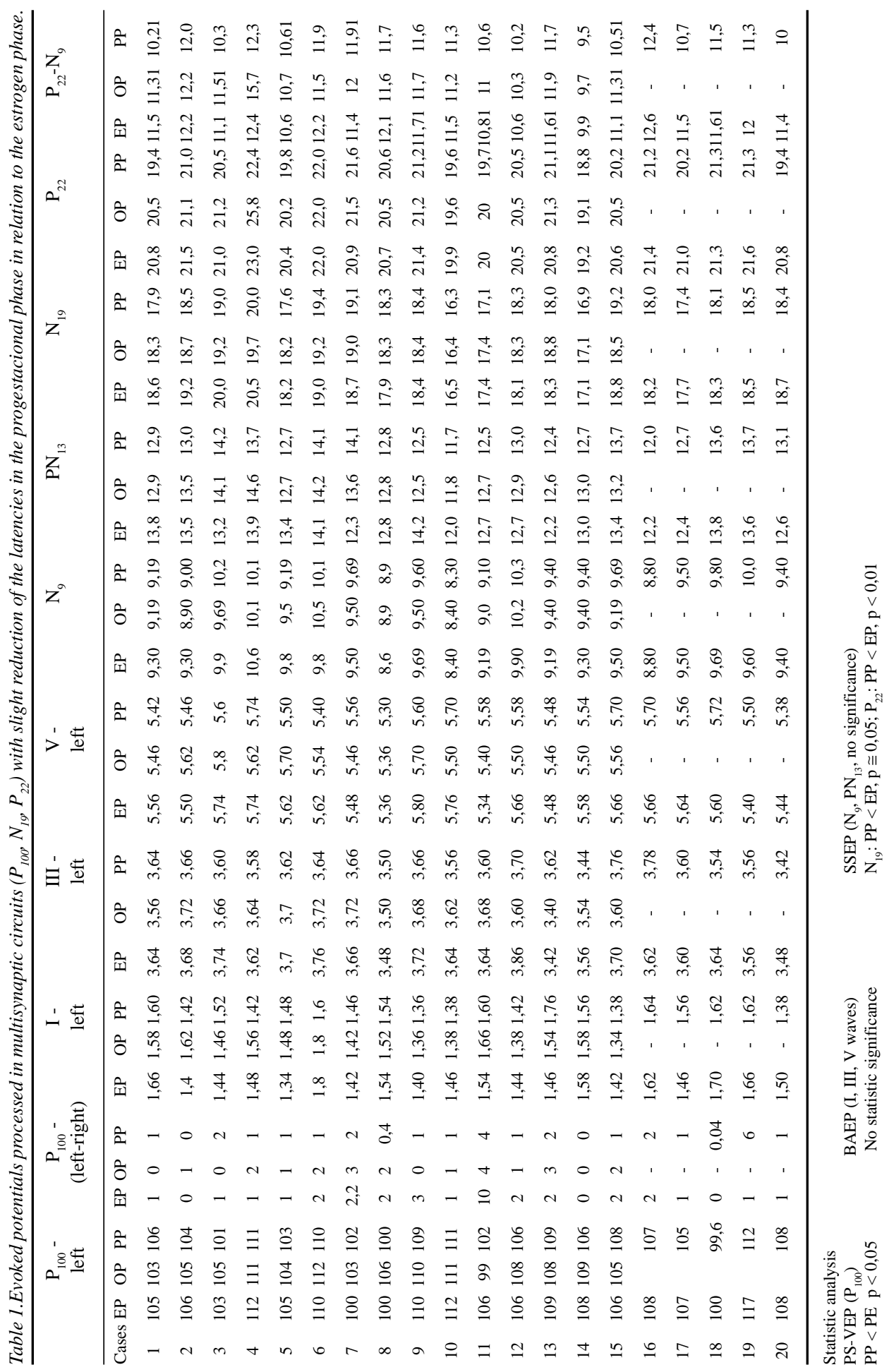




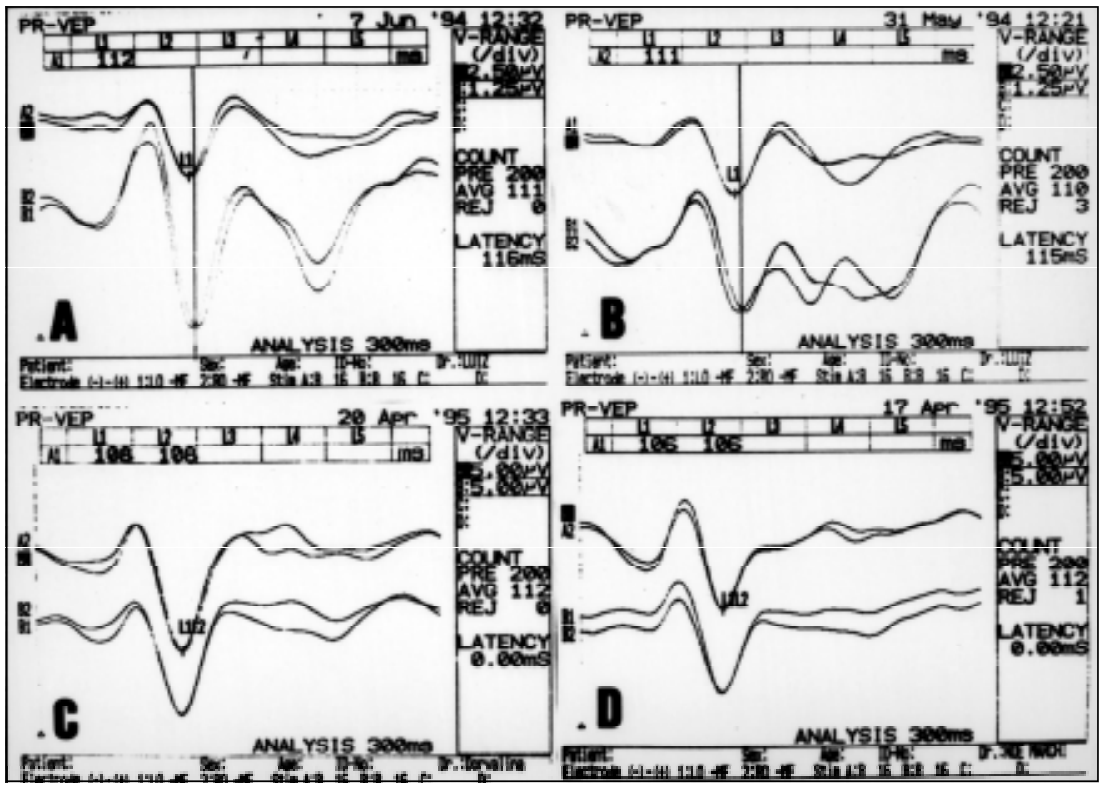

Fig 1. Case 10. Amplitude and latency reduction in the progesterone phase $(B)$ in relation to the estrogen phase (A). Case 14, the same (D progesterone phase, C estrogen phase).

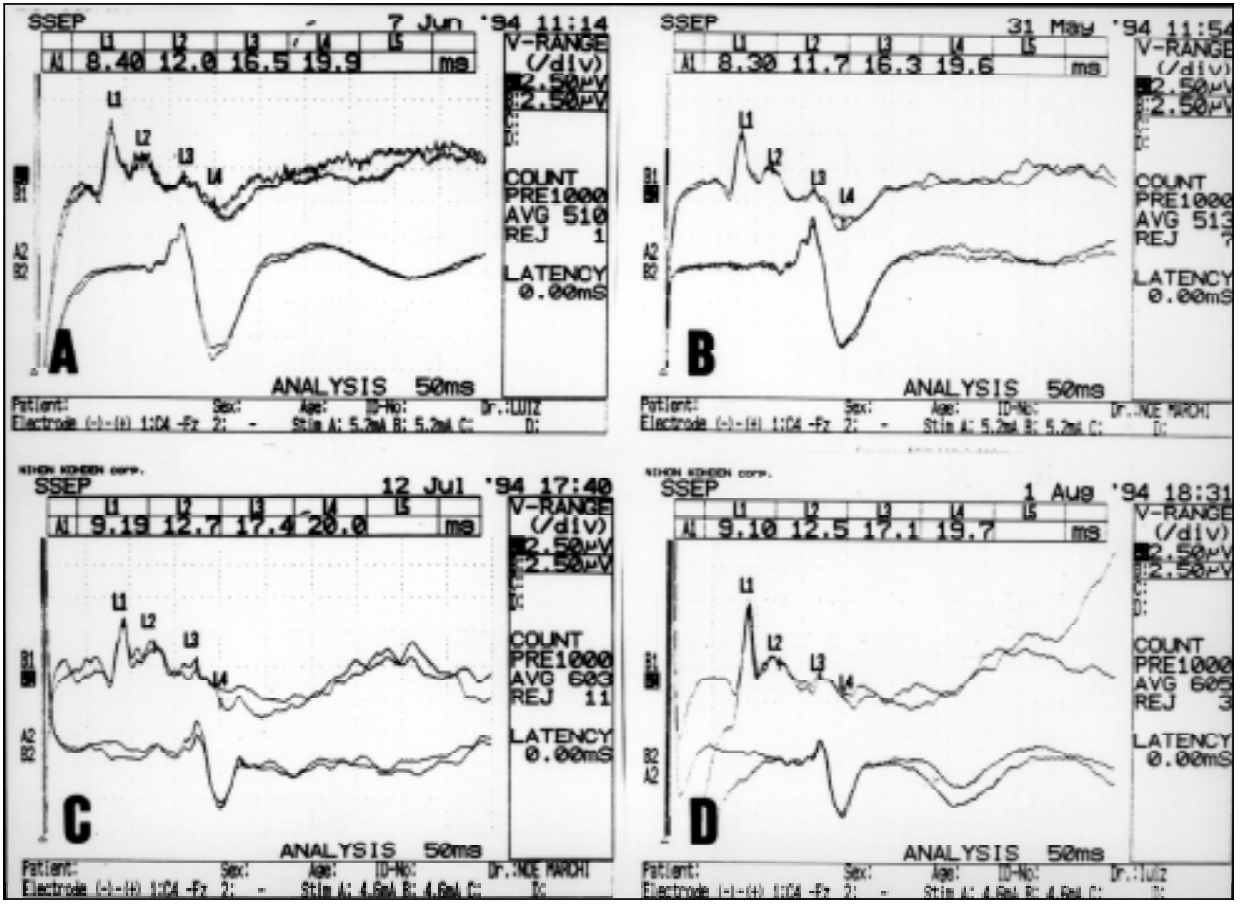

Fig 2. Case 10. Slight reduction of the $N_{19}$ and $P_{22}$ latencies in the progesterone phase $(B)$ in relation to the estrogen phase (A). Case 11, the same (D progesterone phase, C estrogen phase). 


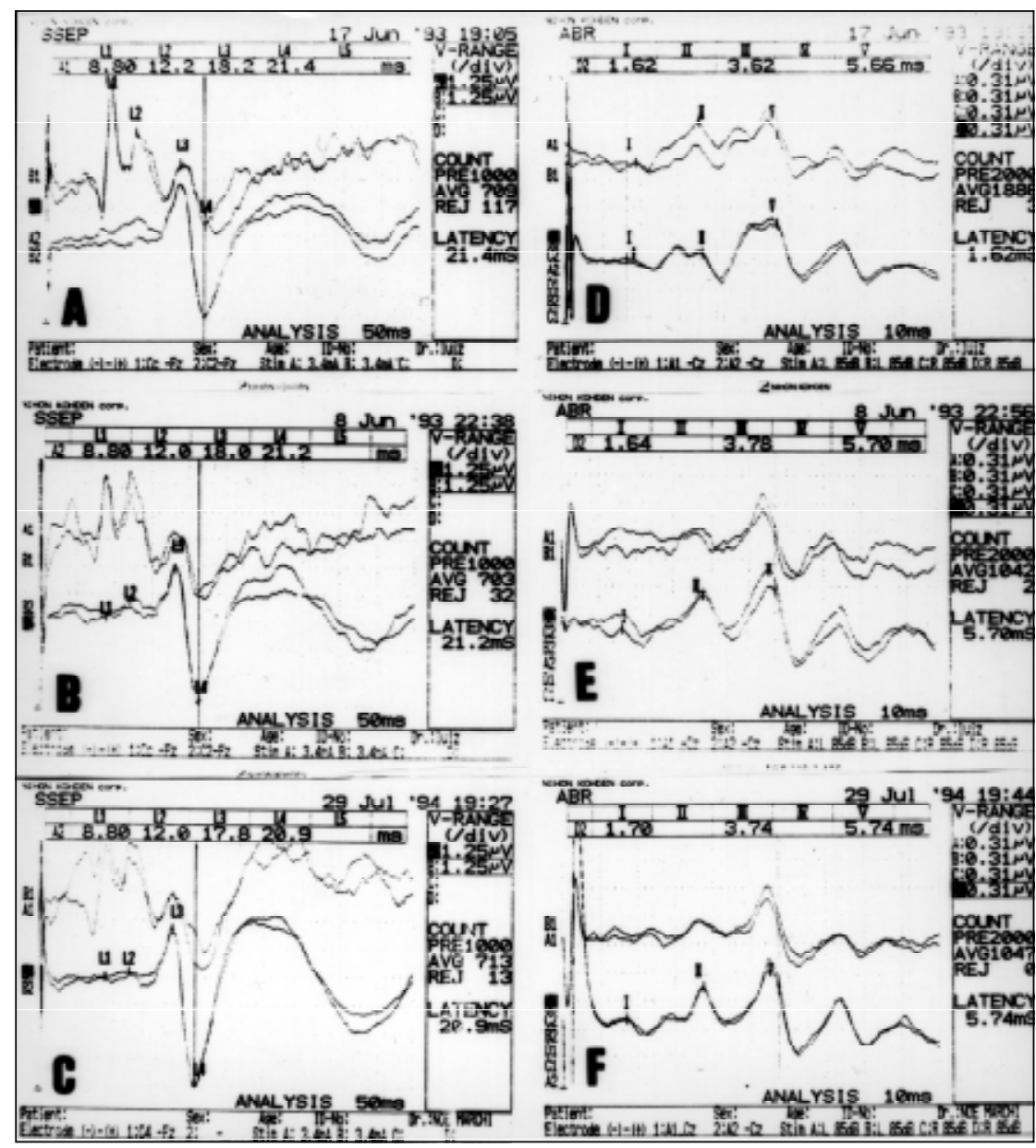

Fig 3. Case 16. Slight reduction of the $N_{19}$ and $P_{22}$ latencies in the progesterone phase $(B)$ in relation to the estrogen phase $(A)$. In pregnancy $(C)$ a major reduction was found. In the BAEP the morphology observed in pregnancy $(F)$ was similar to progesterone phase $(E)$. Both $(F$ and $E)$ are different from the estrogen phase (D).

\section{DISCUSSION}

Latency reductions in the visual $\mathrm{P}_{100}$ and somatosensory $\mathrm{N}_{19}$ and $\mathrm{P}_{22}$ evoked potentials in the third, progesterone, phase of the cycle are complex. It has been demonstrated that even in women using combined anovulatory therapy, significant follicular activity with luteinization occurs, with or without ovulation ${ }^{13}$. Thus, even with the determination of the luteinizing hormone (LH) and ultrasonography, it is not possible to determine precisely what is the hormonal moment of the menstrual cycle. In this study there was no distinction made between a precocious and late luteal phase, which makes it difficult to affirm that latency changes are related to the progesterone phase. Experimental studies have not demonstrated that conjugate estrogens, applied topically or intravenously, affect the latencies of visually evoked potentials ${ }^{14}$.

It is important to point out that the the $\mathrm{P}_{100}, \mathrm{~N}_{19}$, and $\mathrm{P}_{22}$ potentials are generated in multisynaptic pathways, and that the observed reduced latencies during the progesterone phase are probably caused 
by progesterone action on neuronal circuits. On the other hand, it could be hypothesized that the anatomical pathways in the I, III, V, of the BAEP and $\mathrm{N}_{9}, \mathrm{P} / \mathrm{N}_{13}$ of the SSEP are less susceptible to hormonal fluctuation. The reduction of the progesterone phase latencies generated in multisynaptic circuits provides a neurophysiological basis for understanding the human pre-menstrual syndrome. Further studies are required to confirm the above findings.

\section{REFERENCES}

1. Kemmett D, Tidman M J: The influence of the menstrual cycle and pregnancy on atopic dermatitis. Br J Dermatol 1991;125:59-61.

2. McDonagh J E, Singh M M, Griffiths, I D. Menstrual arthritis. Ann Rheum Dis 1993;52:65-66.

3. Ask-Upmark E. Monthly periodicity of symptoms from the central nervous system. Neurology 1955;5:584-586.

4. Ravindran P, Raj R J, Parameswaran K. Concurrent catamenial hemothorax and hemopneumothorax. Chest 1993;103:646648.

5. Bettucci D, Cantello R, Gianelli M, Naldi P, Mutani R. Menstrual migraine without aura: cortical excitability to magnetic stimulation. Headache 1992;32:345-347.

6. Guerreiro C A M, Ramos M C. Premenstrual seizure increase. Arq Neuropsiquiatr 1991;49:27-32.

7. Silberstein S D. Menstrual migraine. Headache 1992;32:312-313.

8. Creutzfeldt O D, Arnold P M, Becker D, et al.. EEG changes during spontaneous and controlled menstrual cycles and their correlation with psychological performance. Electroenceph Clin Neurophysiol 1976;40:113-131.

9. Elkind-Hirscht KE, Stoner BA, Stach BA, Jerger JF. Estrogen influences auditory brainstem responses during the normal menstrual cycle. Hearing Res 1992;60:143-148.

10. Howard R, Mason P, Taghavi E, Spears G. Brainstem auditory evoked responses (BAERs) during the menstrual cycle in women with and without premenstrual syndrome. Biol Psychiatry 1992;32:682-690.

11. Marcus E M, Watson W, Goldman P L. Effects of steroids on cerebral electrical activity. Arch Neurol 1966;15:521- 532.

12. Chiappa K H. Evoked potentials in clinical medicine. 2Ed., New York:Raven Press, 1990.

13. Marsh MS, Smith S. Differences in the pattern visual evoked potential between pregnant and non-pregnant women. Electroenceph Clin Neurophysiol 1994;92:102-106.

14. Van Der Does J, Exalto N, Dieben T, Bennink HC. Ovarian activity supression by two different low-dose triphasic oral contraceptives. Contraception 1995;52:357-361. 